\title{
Dress up and What Else? Girls' Online Gaming, Media Cultures and Consumer Culture
}

\author{
Giovanna Mascheroni ${ }^{1}$ \\ Università Cattolica del Sacro Cuore, Dipartimento di Sociologia, Italy
}

\section{Francesca Pasquali}

Università degli Studi di Bergamo, Dipartimento di Lingue, letterature straniere e comunicazione, Italy

\section{doi:10.5937/comman1329079M}

Summary: In order to investigate how online activities and digital cultures mediate children's socialisation to consumer culture, this paper discusses the findings of a research project on online games for tweens which focus on fashion. Popular websites for girls include a variety of games centred on fashion; these are mainly paper dolls sites, which engage girls in a drag and drop activity of clothes and fashion items on sexualised bodies, at times of celebrities. Some reproduce fashion and beauty ideals in settings such as catwalks, hairstyle and beauty saloons, etc. Others, such as Stardoll.com, offer more complex environments, integrating dressing up activities with the creation of an online persona, combined with social networking. Drawing on analysis of online dress up games and websites, and a set of group interviews with young girls aged 9-13, the paper explores how tweens engage with these games and, more generally, how they appropriate, negotiate and resist consumer culture through the practice of dressing up themselves and their online personas. The aim of the paper is therefore threefold: 1) reconstruct the meanings and uses of online paper dolls websites, and their symbolic value in everyday interactions; 2) investigate how these games contribute to shape young girl' engagement with digital cultures, consumer and celebrity culture; and 3) understand how stereotyped representations of young girls as consumers circulated in media, consumer and celebrity culture are socially made sense of by tweens in their peer cultures.

Keywords: dress up games, Stardoll, tweens, celebrity culture, children and consumer culture

\footnotetext{
1 giovanna.mascheroni@unicatt.it
} 


\section{Introduction}

Popular websites for girls worldwide include a variety of games centred on fashion: these are mainly paper dolls sites, which engage girls in a drag and drop activity of clothes and fashion items on sexualised bodies, sometimes of celebrities (such as Lady Gaga, Britney Spears etc.). Others reproduce fashion and beauty ideals in settings such as catwalks, hairstyle and beauty saloons, etc. In addition to these casual gaming sites where interaction is mainly with virtual dolls presenting a rather fixed set of features (skin and hair colour, make up, clothes etc.), there are more immersive and complex virtual worlds where the game is performed through avatars and the player is the doll. The most popular is Stardoll.com that integrates dress-up activities with the creation of an online persona, social networking and other forms of communication (such as a thematic forum) or gaming. Stardoll is a community, where girls can build their own profile, have a 'bedroom', visit their friends' rooms, send and receive messages, chat, and share their creations on Facebook.

The Stardoll community is also emblematic of the increasing commodification of childhood (Buckingham, 2011), its supposed sexualisation and the increasing influence of celebrity culture on pre-adolescence. It includes a shopping mall, Starplaza, where girls can shop for some popular offline brands to equip their dolls' wardrobes, and a vintage boutique, called Star Bazaar. In order to gain starcoins to spend in the shopping mall, girls are asked to dress up celebrities (from Hannah Montana to the Queen Elizabeth), but they can also design their own clothes and accessories, which can then be marketed in the shopping mall. Most of the clothes reproduce the normative sexualised outfit that is increasingly characterising the market of clothes for pre-teens: short tops, close-fitting jeans, mini-skirts or shorts, high heel shoes etc. It is, therefore, an immersive online environment, integrating social networking activities - which are widely popular among young girls (Livingstone et al., 2011; Madden et al., 2013) - with creative uses of the internet - which are less popular and at the top of the ladder of online opportunities that children climb according to age and online experience. The ladder of opportunities, indeed, identifies a progression from basic online activities - such as information seeking for schoolwork, gaming and watching videos - to more creative and participatory uses, whereby the more children use the internet, the wider array of opportunities they take up, and vice versa) (Livingstone and Helsper, 2007; Livingstone et al., 2011). 
Despite the differences both in the type of interaction allowed and in the type of reflexivity at stake (Boccia Artieri, 2012), dolls and avatars' dress up games share some common roots and are positioned in similar continuum of game/ consumption practices. They, indeed, can be positioned within a line of remediation of a very old cultural artefact through that paper dolls (started to be published in fashion magazines in late XIX century) links the poupées de mode with the Barbie (Peers, 2004).

Moreover, as it will be argued in the following pages, both dolls and avatar dress up games are embedded in a complex set of symbolic and material consumption that links factual television, brands and advergaming, offline shopping and dwelling in shopping areas, and celebrity culture.

\section{Background literature}

Over the past two centuries, the meaning and making of childhood has been radically reconfigured. A variety of factors concurred to shape changing notions of both childhood and parenthood: transformations in the family structure (Luke, 1989); the idealised construction of childhood as a distinct and innocent group in need of protection (Zelizer, 1985), and the related discursive construction of parenthood as responsible for this segregation/protection; the rise of a market of consumer goods specifically for children and the emergence of a children's consumer culture (Jacobson, 2004; Denisoff, 2008) are some of the most powerful changes. Having their roots at least in the second half of the 19th century, these developments have become prominent in recent years, when the figure of the child consumer has been the focus of increasing public concern and moral panic. Indeed, though a market of goods for children can be traced back to the eighteenth century (Plumb, 1982), nonetheless children have long been marginalised within consumption studies (Cook, 2008) and have apparently been "discovered" by marketers in the last three decades through the discursive production of youth as "others" from adults and as belonging to smaller markets segmented along the lines of age and gender (Coulter, 2012). As a consequence, childhood has been fragmented into distinctive niches (toddlers, tweens and teenagers; boys vs. girls) that fit with the needs of the marketplace; while age and gender differences are privileged and emphasised, distinctions in class, ethnicity or sexuality tend to be overlooked (Coulter, 2012). The new market category of the "tween girl" "describes a girl falling in between 
infancy and adolescence who, by implication, anticipates adolescence as much as she remains firmly in childhood", and it puts into question the idea of a clear-cut boundary between infancy and adolescence (Driscoll, 2008: 24). The tweens category also embodies the very contingency of the category of girlhood, and it "newly engages a very familiar set of questions for girl studies: questions about how gender identity is developed and organized; the developmental role and limits of girlhood; and the relationship between pleasure, commodities, femininity and ideology" (Driscoll, 2008: 25). Moreover, it renovates concerns for the sexualisation and commodification of childhood which have long been familiar within girls studies

The debate around the increasing "commodification of childhood" (Cook, 2004) has been polarised into two quite contrasting constructions of the child consumer. A critical perspective on consumer culture blames both corporate marketing and the media as the most powerful forces corrupting the innocence of childhood. Within these claims, children are represented as vulnerable and powerless victims of the insidious manipulations of both advertising and media. An alternative perspective has emerged in marketing discourses by celebrating children's empowerment through consumption, their competence and sophisticated needs: children are active, media-savvy and demanding consumers, and thus far from being passive victims.

The "disappearance of childhood" and the "empowered child" perspectives (Buckingham, 2011) not only construct alternative positions of children visà-vis consumption, they also raise relevant issues concerning the positioning of children in society, their agency, as well as the role of media in children's consumer culture. In other words, these polarised representations rest upon equally polarised notions of childhood.

The dominant theoretical and research paradigm in childhood studies adheres to the developmental psychology's approach (Piaget and Inhelder, 1969) by conceiving childhood in terms of "ages and stages" as a linear progression towards entry into adulthood. Children, hence, are understood as "becoming adults" which means incomplete and incompetent social actors with respect to adults (James et al., 1998).

In response to the effects tradition and the stage-based approach to the study of childhood, over the past two decades the so-called new sociology of childhood has shifted away from the idea of children as adults-in-the-making 
and repositioned children as "beings" in their own right, full social actors with their distinctive cultures (Corsaro, 1997; James et al., 1998; Harden et al., 2000). This view of children as active agents resonates with marketing accounts of consumptions as a means of empowerment. At the same time, however, the new sociology of childhood rejects the notion of the (child) consumer as an isolated individual, and is primarily concerned with emphasising the cultures and social environments that children create for themselves.

The polarised dichotomy between children as becomings and children as beings - as well as children as passive victims of marketing vs. children as skilled and sophisticated consumers - has been recently replaced by an alternative approach, one which appropriates and extends to childhood the sociological debated over identity and individualisation. According to these theories, identity is not a fixed possession and stable entity, but rather a process that is constantly and reflexively made and reworked through everyday practice. It is, furthermore, a social process in the sense that the individual and the social are intertwined, and identities are always social. As it concerns youth's identity, this means that rather than simply being children or becoming adults, children are engaged in "doing childhood" (Solberg, 1996).

A child-centred and contextualised approach is also adopted by Pugh (2009) in her ethnographic study of the practices and meanings of consumption in American families. She advances "a third way [beyond the dichotomy passive vs. active consumers] of viewing consumption, as part of children's meaning-making that borrows from but does not replicate corporate-made culture" (2009: 217). Without neglecting the influence of advertising nor children's cultural creativity, she understands material and cultural consumption in terms of symbolic tokens on which children rely in their interactions in order to belong to their peer groups, in what has been defined an "economy of dignity" (Pugh, 2009). The focus on meaning-making and the inclusion of goods within children's symbolic repertoires resonates with the work of media scholars in their studies of children's engagement with the media. Both consumer culture and the media provide a symbolic repertoire of meanings, values and practices through which children perform, negotiate and narrate their identities; shape relationships with their peers and mark the boundaries of inclusion and exclusion. For children growing up in the consumer culture, "identities are 
increasingly defined through the often transient markers of lifestyles and media practices" (Livingstone, 2009: 12), and so is belonging (Pugh, 2009).

Digital media have become a pervasive component of children's lives in contemporary Western societies: children grow up in a convergent media ecology (Ito, 2009), whereby a variety of everyday practices - self-expression, sociability, learning, games, cultural consumption, etc. - take place. Contrary to what is argued by media panics inspired positions (which emphasize the fear that online, mediated relationships are replacing offline, 'authentic' interactions) "children are integrating the online and the offline" (Livingstone, 2009: 31) in seeking to develop a coherent project of the self. In other words, we must recognize that this media ecology is part of a broader social and cultural ecology that children inhabit rather than conceptualizing the media as a cause in youths' lives, we call for a contextualization of media practices within children's own worlds (Livingstone, 1998). Childhood - which is increasingly mediated - and the media environment are both changing in late modernity (Livingstone, 2009) and co-determining each other. This process of mutual shaping is altering the conditions under which identities are constructed and represented (Buckingham, 2008); more specifically, this new media ecology is implicated in the process of individualisation of the relationship with traditional institutions - family, education, religion, politics etc. - and, with respect to youth, it certainly sustains the increasing importance of peer networks and online communities in the process of producing, negotiating and representing identities.

In this respect, therefore, the perspective of media studies on youth and childhood (Buckingham, 2007, 2011; Drotner and Livingstone, 2008; Livingstone, 1998, 2002, 2009), the research on youth's bedroom culture (Lincoln, 2004, 2013) and Pugh's (2009) seminal work on the economies of dignity all provide a child-centred framework for understanding youths' everyday practices (on- and offline) as contextualized "within concentric circles of structuring social influences", which shape children's agency (Livingstone and Haddon, 2012): family, community and culture (Bronfenbrenner, 1979). A "cultural sociology of the child consumer" (Buckingham, 2011), then, entails adopting a child-centred approach and moving beyond the dichotomy of structure and agency, in order to see how structure and agency act through each other (Giddens, 1984). The agency offered to (child) consumers is moulded and shaped by structures - e.g., by the power of corporate marketing and consumer cul- 
ture, which position the individual as a competent and empowered consumer. Hence, the practices of consumption, in which children engage at ever younger ages are both normative and creative, and constraining and personalised.

\section{Research questions and methods}

Drawing on the theoretical framework above outlined, a qualitative research was designed in order to address the following issues: 1) reconstruct the meanings and uses of online paper dolls websites, and their symbolic value in everyday interactions; 2) investigate how these games contribute to shape young girls' engagement with digital, consumer and celebrity cultures; and 3) understand how stereotyped representations of young girls as consumers circulated in media, consumer and celebrity culture are socially made sense of by tweens in their peer cultures.

To achieve these goals, five group interviews with young girls aged 9-13 (2-3 girls in each group, for a total of 12 girls) were conducted. The choice of qualitative methods is consistent with the cultural and critical approach to the study of girls' relationships with cultural artefacts adopted within Girls Studies (Mazzarella, 2013). With respect to the sample, a theoretical assumption laid behind the choice of interviewing two or three girls who are classmates, siblings and/or friends. Since we are interested in the process of peer negotiation that characterises both media and consumer cultures, and in the use of material and symbolic goods as tokens for everyday interactions, we selected girls who shared at least one everyday life context and its associated activities. The participants were therefore selected through a theoretical sampling procedure starting from the researchers' own social networks (namely, colleagues with children in the same age-group, who provided access to their children's schoolmates, or acquaintances with teenage children). To avoid over-representing certain categories and balance the risk of too much homogeneity in terms of families' sociocultural background, the researchers combined different criteria such as area of residence and social class: more specifically, three groups involved girls living in the centre of Milan and belonging to the middle- and upper-middle class; one in a middle-class suburban residential area; one in a less advantaged and multiethnic neighbourhood; and one in a town located 15 kilometres form Milan, in a semi-central, lower-middle class area. 
The interview schedule focused on online gaming practices, but also covered other issues: online activities more in general, such as the engagement with celebrity and consumer culture through dedicated websites and formats (such as tutorials on YouTube); engagement with media culture and products such as lifestyle television; and practices of dressing up and putting on make up.

Interviews took place in a domestic context (the home of one of the interviewees) and lasted from one hour to one and a half hours. Interviews were audio-recorded and transcribed in full. Transcriptions were coded independently by the two authors, and then systematically analysed by both.

\section{Consumer culture, media culture and gender identity}

Paper doll websites cannot be simply analysed as gaming practices isolated from other media or consumption practices. Indeed online dress up games are located within a nexus of commercialised practices that operate across online and offline worlds, and which spread over different media platforms. Combined, these resources provide a toolkit for managing identities and experimenting with patterns of adult femininity since they socialise young girls to the codes of dressing up and putting on make up. Interviewees remark on the strong continuity between online and offline worlds in terms of skills, practices, and identities (though highly stereotyped identities and lifestyles, as we will discuss later):

It is like real life, you have your own house (Anna, 12 years old) Meet friends (Anita, 9 years old)

You select furniture, rent the house, relocate, have a dog and a car. And you also manage money (Anna, 12 years old)

yes, like when in this big shopping mall there's a new shop or some shop has sales they send you an email alert, and pictures and so on. You can log into your page directly from the email and they show you the shop (Eleonora, 11 years old) like in real life (Chiara, 11 years old)

and I like it because it's like when you go shopping for yourself but there is a greater variety and you don't pay with real money (Alice, 11 years old)

These games provide young girls with some very practical skills. First, young girls attribute to paper doll websites the ability to match colours in a fashion- 
able and appropriate way, and which mark a shift from childhood to pre-teens (coinciding with the passage from primary school to lower secondary school):

Interviewer: you were saying these games helped you... in what sense? matching colours, before I used to match green and red... I improved a bit my clothes, I was a disaster before, I mixed all the colours (Cecilia, 12 years old)

I found a new way of wearing shirts, with a bow here, which masks it is a long sleeves shirt. One learns, it's cool (Nadia, 12 years old)

The ability to create an appropriate outfit by matching colours and pieces of clothes is the outcome of both the increased engagement in gendered practices such as shopping, in the offline world (Marsh, 2010) and of crossmedia consumption. Interviewees report watching factual TV formats such as "What not wear", reproduce the proposed outfits first on Stardolls and similar games, and later incorporate those elements in their everyday life clothing. The same interplay between lifestyle television, online gaming and everyday life emerges in relation to the practice of putting on make up:

what we like about these games... we like to dress up, match clothes, create clothes. Because I also like watching fashion programmes, so you watch on TV, go to Stardoll and try to reproduce that look. Yes, because at the end "What not to wear", it is all a "this is right, this is not", and so you go on Stardoll and recreate the outfit (Anna, 12 years old)

yes, it is funny (Giulia, 12 years old)

I also look for websites where you learn how to put on make up, things like that (Cecilia, 13 years old)

yes, also because there are programmes, on Realtime channel, on $T V$, such as "Clio makeup" where they teach you how to put on make up, or "What not to wear", that kind of things (Carolina, 13 years old)

or tutorials on Youtube (Cecilia, 13 years old)

Through the provision of practical skills, those sites, along with Lifestyle television and online tutorials and how-to videos (on make up, nails, dress, hair etc.) thus provide young girls with a space where to safely experiment with the norms regulating the construction of (a more adult) femininity through cloth- 
ing and make up by being a place where fashion is socialised among peer culture and the ideal self is staged.

At the same time, it is clear that Factual TV, dress up games and online tutorial offer a toolkit for the making of the ideal self. Tweens project on their dolls and in their avatars all the expectations, aspirations and fears of growing up and becoming an "appropriate", "perfect" young woman:

Normal people go on Stardoll. You see that piece of clothing you like, and perhaps you have a similar skirt at home, a similar t-shirt, so you try it on, and if you like it, you can wear it (Anna, 12 years old)

Interviewer: so Stardolls and other games can inspire you, as you said about tv programmes?

yes, because you create the perfect person, perfect I would say, so you can be a bit like her. On Stardoll, you can create your ideal person, so as you would like to be (Anna, 12 years old)

Interviewer: where did you get inspiration for the doll that you usually use? You said you were imagining yourselves? yes, as we would like to be (Chiara, 11 years old) me, rather than how I would like to be, it is how I would like to dress up... because I am happy with what I am. But I would like to dress up in different way, I'd like to wear dresses, but I don't feel comfortable when I wear them, instead on my doll I like them (Alice, 11 years old)

As anticipated, moreover, experimenting with the self takes place in a highly commercialised and stereotyped framework through which girls are socialised to the normative character of fashion and consumer culture in the construction of gender identity - as pointed out by feminist scholars, who understood the so-called "girl power" as an inclusion of feminist discourse within contemporary consumer culture and mainstream media culture that reduces and annihilates its conflicting power (Lemish, 2003; McRobbie, 2008).

Despite the plurality of female models and the general acceptance of the active role of women in constructing their gender identity, women are essentially mobilised as consumers (McRobbie, 2008), and are enforced to conform to an aesthetic ideal of femininity: "femininity itself is an aesthetic phenomenon." (Russel and Tyler, 2002: 629). Consumer and media cultures promote an ideal 
of 'sexy' woman, where sexuality is "both thinkable and recognizable through fashion items such as crop tops, thongs, low-rider jeans, tiny bikinis, and provocative T-shirts" (McRobbie, 2008: 545).

Feminine aesthetic models and roles are played and staged without any discussion, and interviews show an acritical adhesion to stereotyped patterns of femininity: the ideal of a white, tall, thin but sexy woman is normalised and taken for granted:

I created a normal girl, not anorexic! she is tall, she looks more or less like a top model (Anna, 12 years old)

yes, I chose a normal body type too (Anita, 9 years old)

Interviewer: and you told me you can change the colour of the skin? yes, you can make it tanned, pale as a ... or normal When you create your online character you start from body shape: tall, thin, or fatty. The next step is the face, you choose eyes, if you like the Asian shape, or the round shape, such as a cartoon. Then you pick long or short hair, brown, or blonde or red... as you want! And finally you select clothes (Anna, 12 years old) you can also add wrinkles (Anita, 9 years old) you do, yes, but you add wrinkles just for fun, if you create our ideal woman I don't think you want it wrinkled, do you? (Anna, 12 years old)

you can decide if you want to be fat or thin (Eleonora, 11 years old) tall or small (Chiara, 11 years old)

Interviewer: have you ever seen a fat doll?

yes, disgusting, disgusting. Because you can enlarge your shoulders (Eleonora, 11 years old)

and if you enlarge your shoulders then your breast and bottom get bigger too (Chiara, 11 years old)

and the final result is... I don't think anyone would like to be like that, even girls who are fatty I don't think they would like to be exactly as they are on Stardoll. Because I think on Stardoll people look for the perfection they cannot reach in real life (Eleonora, 11 years old)

and then you can be skinny, or on average, normal as my doll is, or fat. If you choose the skinny type then you are... how can I say? Childish, with nothing on (Chiara, 11 years old) 
Moreover, the larger cultural framework that exploits the language of choice ("you decide if you want to be fat or thin") is not discussed. Dress up games are the quintessential place where young girls "choose to conform" (Stuart and Donaghue, 2012) to specific beauty and fashion models and at large to neoliberal post feminist hegemonic idea of an autonomous self-regulating and self choosing feminine subject. A subject whose self-confidence is associated with external appearance in a shift described as a shift from "sexual objectification to sexual subjectification" (Gill, 2003).

Though the normative patterns are taken for granted however, pre-teens discursively negotiate aesthetic stereotypes and hyper-sexualised femininity. Our findings are consistent with prior research on the doing of gender and age through fashion among pre-teens and their understanding of apparently sexualised clothing, which warn against interpretations of sexualisation as a linear cause-effect process (Pilcher, 2010; Rysst, 2010). First of all, interviews show how 'what to wear' remains structured by their social context and experiences. While gaining pleasure from dressing up on and offline as a way of ageing up, pre-teens are aware that fashion models proposed in online gaming and media culture are inappropriate for their age:

Interviewer: do you think the clothes on Stardoll are for girls of your age? not really (Anna, 12 years old) they're for adult women, in between their 20s and 30s [...] it is clothes that you like but you cannot wear, because they are for older girls. They don't think of younger teens... (Giulia, 12 years old)

I'll never go out with high heels before 16. It would be rather... I miss the word (Carolina, 13 years old)

not normal (Cecilia, 13 years old)

yes, not normal! (Carolina, 13 years old)

on Stardoll you find clothes that you don't find in real life. Or when I see something in real life I fancy but I wouldn't wear it at school... but online I can buy it because my doll can wear it... there are more eccentric clothes (Alice, 11 years old) some clothes you can find them in real life too, but not everywhere, it is difficult (Chiara, 11 years old) 
it is diffcult and I wouldn't wear it because I would feel uncomfortable (Alice, 11 years old):

then there are temporary shops where you find very expensive clothes in limited edition, that you would never find in real life apart from Gucci and Prada and catwalks, those kinds of clothes which are impossible to wear, but on Stardoll you can wear them because they're eye-catching! (Eleonora, 11 years old)

Like Barbie before them, these games introduce tweens to a highly stereotypical model of adult femininity; in continuity with Barbie, moreover, dress up games "not only are gendered but are also a game about gender" and age (Driscoll, 2005: 226). From the one side, these games introduce young girls to an ageless girl culture where beauty practices, body makeovers and shopping play a fundamental role in building a post-feminist identity that fit from tweens to women in their 30s and 40s. But at the same time, dress up games are a playground where "tweens play teens" (Mitchell and Reid-Walsh, 2005: 3) and start to perform within the reversible transition from girl to woman and woman to girl (Driscoll, 2002). Young girls play within this continuum. They perform it, but at the same time, they rework and resist it through negotiating discourses on beauty and sex within a wider context of socio-cultural regulations (Renold and Ringrose, 2011). The girl/woman continuum is thus problematised within everyday life "age specific" activities, needs and problems. In this perspective, dress up gaming platforms are reconceptualised as "growing-up" playing activities and become a kind of "private" playground where to cope with a body that is changing and with different expectations and definition on what is appropriate and what is not for a young girl.

Moreover, pre-teens develop socially-shared norms that lead them to define sexualised and provocative clothing as an unwanted effect and inappropriate for girls of their age and their body shape, and for specific social contexts such as school. Not only are revealing clothes uncomfortable pieces of clothing to wear at school, which contrast with school norms, but pre-teens report avoiding these clothes as they may trigger unwanted sexual comments from boys and as violating their sense of modesty. Therefore, girls expressed a reflexive understanding of "what to wear" as contingent and dependent upon contexts

those revealing tops (Chiara, 11 years old):

that we would like to wear but are not allowed to (Alice, 11 years old) 
cloths on these games... sometimes, often, are not the clothes you would wear at school. I use to wear in a sober way at school, I don't like when other people look at me (Cecilia, 13 years old)

a T-shirt and jeans. Sometimes at school you see girls wearing such high-cut shorts, which make me say "I'll never go to school like that", even because boys tease you (Carolina, 13 years old)

I wouldn't use them either in my leisure time, apart from the seaside (Cecilia, 13 years old)

yes, because boys look underneath, they behave as idiots and look underneath (Nadia, 12 years old)

I don't like wearing skirts at school (Giulia, 9 years old)

it's not comfortable (Alessia, 11 years old)

I wear skirts just if I have shorts underneath (Giulia, 9 years old)

The discussion of sexualised feminine stereotypes also calls into question the relationship of pre-teens with celebrity culture. On one side, girls position celebrities at the centre of their (online) identity work:

I enjoyed creating avatars that looked like celebrities. Or I created an avatar, gave her a name, and the name was associated to her personality, I enjoyed reconstructing the story of her life me (Cecilia, 13 years old)

when I find another doll or a celebrity I like I try to look like her in everything (Eleonora, 11 years old)

However, with respect to the commodification of celebrity culture, preteens invest in cultural icons such as pop stars and sports stars, but engage knowingly in the lifestyle proposed in order to find their own style (Boden, 2006), and girls are especially aware that femininity can be "excessive" and needs to be regulated (Russell and Tyler, 2002):

you cannot go around half naked! like pop stars, such as Paris Hilton, for example, with those tops, she is half-naked (Alessia, 11 years old) 
they are exaggerated, the want to be noted! Once I saw one wearing a bandeau bra, shorts and boots, and walking on the street as if it were normal (Nadia, 12 years old)

Interviewer: where have you seen it?

for example on bambini.eu, and every week, every Friday, there's the latest look of celebrities, such as Ashley Tildey, and she is too glittered, too pink, with a dressed up dog!! (Nadia, 12 years old)

Lady Gaga is too odd! (Anna, 12 years old)

Miley Cyrus is one who wears daring clothes... she wears shirts that reveal the bra or too high cut shorts (Cecilia, 13 years old)

The ways in which girls talk about (un)dress codes of the female celebrities they engage with works as a site for the production and negotiation of subjectivities. Celebrities thus provide to be widely accessed resource for constructing identity (Boden, 2006), but again it is a resource that resonates within a complex reflexivity that generates within gaming performances and peer culture.

\section{Making sense of symbolic and material consumption in everyday life}

Online gaming, offline dressing up and consumption practices are incorporated by tweens in their everyday relationships with peers so as to mark the boundaries of group belonging and, at the same time, claim status and individuation within the group. Indeed, both online and offline practices are continuously negotiated and made sense of in interactions with peers and adults. The negotiation among peers draws attention to what Buckingham (2008) calls the paradox of identity. In the construction of their identity, pre-adolescents seek to balance their claim for uniqueness with the need for identification with others. Moreover, the use of these practices as symbolic tools for the construction of both identity and in-group relationships responds to the mainstream imperative on consumer culture, which prompts individuals to maintain a distinct cultural identity (Heath and Potter, 2005; Willett, 2008)

Online gaming is an activity which binds tweens together. As the interviewees report, online dressing up offers the basis on which friendship ties are formed and forged through time 
yes sometimes Carolina and I, who were best friends at primary school, and still are best friends, we are used to showing each other's profile, we talk on the phone... we keep updated with the game ... mostly at school (Cecilia, 13 years old)

I discovered these girls games on the internet two years ago when I first met them. I remember it was summer and we met down in the courtyard, we started playing Barbie together, then they invited me to their place, and they showed me a lot of games on the internet (Nadia, 12 years old)

Interviewer: and how did you find them?

as I said before, we typed in 'games' (Giulia, 9 years old)

Interviewer; and how old were you?

I guess I was 7 (Alessia, 11 years old)

I learned to play these games when they did, when I met them, so I was 8 and she was 7, so... (Nadia, 12 years old)

As the excerpt above suggests, however, in everyday interactions online paper dolls websites and associated activities also serve as tokens which confer the dignity to take part in talking and to make claims: by referring to their engagement with digital media, and consumer culture young girls do not only claim their right to belong to the group, but indeed, they also claim their right to distinction and individuation. The following transcripts reveal how both distinctive features within the Stardoll community - the subscription which grants the status of Superstar - and the ability to spend the skills acquired on paper dolls websites, lifestyle television and other websites - such as the skill to match colours in an appropriate outfit - are combined with individual and social differences and give rise to interactional differences (Pugh, 2009):

Interviewer: so you all have more than one doll. Do you have one you use the most?

yes, the classic one, the one who is Superstar, which means that I am granted access to ... everything! Everything I need I can get (Eleonora, 11 years old) she can shop for clothes (Chiara, 11 years old) that other players are not allowed to (Eleonora, 11 years old) that are more beautiful (Chiara, 11 years old) 
yes I have been begging my dad for two years, and now I've been a superstar for one year (Eleonora, 11 years old) because you have to pay in order to be a superstar (Chiara, 11 years old) yes, you have to pay for it (Eleonora, 11 years old)

Interviewer: and how much is it?

It depends, it is around 5, 6 euros per month, 6 months is... I don't remember, but I remember that it is 47 euros per year. But for Christmas you are given three months more, and clothes and... yes, new rooms... (Eleonora, 11 years old)

I am more critical on clothes than when I was a child. For example, Giulia's clothes don't match, these colours together are disgusting. This very colour is ugly on its own, it is out of fashion (Nadia, 12 years old) that's not true, I always dress like that (Giulia, 9 years old) no, you don't, you were much more pretty yesterday. But last year I didn't care either. Growing up you care more, you keep an eye on your weight, your hairstyle, your make up and what you wear, you look out for stains on your clothes ... it is the shift to adolescence, everybody is clean and stylish, on the internet as well, so it becomes a problem. She doesn't care now, but she will next year.. (Nadia, 12 years old)

What practice, or meaning is valued and confers dignity is contingent and contextual. It depends on the normative and cultural system developed by the peer group, and it is constantly negotiated, contested or re-affirmed in everyday interactions. When young girls break the rules, as when resisting the socially accepted dress code, they do so consciously, in order to claim distinction from their peers:

if now I look at fifth grade girls (primary school), they look like children... and our classmates were normal, but the two of us at the end of the year lost a bit of our normality... (Cecilia, 13 years old)

Interviewer: do you mean that you were no longer children? no, we acted older! (Cecilia, 13 years old) 


\section{Conclusions}

Girl cultures have been traditionally framed through the concept of bedroom culture: the idea that, as opposed to boys' subcultures, girls' subcultures were performed and negotiated mainly, if not exclusively, in the space of the bedroom, as a space which is par excellence private, female and safe, where girls can safely engage and experiment with the pursuit of beauty or finding a husband (McRobbie and Garber, 1976). McRobbie understands the private activities which take place in this safe female space in terms of a mapping out of meanings from girls' media - mainly teenage girls' magazines - which are then re-mapped onto the young readers' lives. The "codes" operating in teenage girls' magazines - the codes of "romance", fashion and beauty, pop music and personal life - socialise girls to stereotyped gendered identities produced by the media (McRobbie, 1991).

Later, studies of bedroom culture, however, pointed to the fluidity of the boundaries between private and public space as well as to girls' agency, thus reconceptualising the bedroom as a space where various practices and media converge and overlap, and which is worked upon by young girls in the active construction of their identities (Lincoln, 2004, 2013). For example, Lincoln introduces the concept of "zoning" to indicate that "young people's bedrooms are key identity spaces that can be understood as a collection of zones. These zones interweave and overlap by flowing one into another from the public to private, and the physical to the virtual reflecting the very nature of contemporary youth culture" (Lincoln, 2013: 318). Accordingly, we understand Stardoll and dress up games as "virtual bedrooms" where girls produce their online identities and engage reflexively with symbolic resources which are then incorporated in the space of the "offline" bedroom and, more generally, within peers cultures. Indeed, the metaphor of the bedroom fits particularly with Stardoll where girls' profiles are identified not only by a particular character they create, but also by the bedroom they decorate, and the wardrobe they fill with clothes. Thus Stardoll overlaps and interweaves with traditional girls' "bedroom" activities such as experimenting with hair, make up and clothes both individually and with some friends in a private and safe space. 
The present study has one main limitation, namely its explorative nature and the involvement of a small sample. However it points to a set of issues that future research might address. As the more recent concept of bedroom culture assumes, the bedroom does no longer provide an exclusively private space, nor is it totally safe. At the opposite, public spaces are increasingly converging and interweaving in the space of the bedroom. In this respect, dress up games are emblematic of the shifting boundaries between the public and private spaces. In fact, they can be understood as risky opportunities since they socialise young girls to the practice of producing, negotiating and representing identities, while exposing them, for the first time, to risky contacts online. Paper doll websites are places where younger girls experiment with online communication practices, experience the first risky contacts with strangers and acquire safety skills and useful strategies to manage their online identity and sociability. The girls interviewed in the present study are aware of the potential negative outcomes of risky contacts and engage in a variety of strategies in order to keep safe the practice of not disclosing personal information to strangers, interrupting the communication when someone becomes offensive, and sharing advice on dangerous profiles. These are valued and shared in girls' culture. The relationship between online risks, gender identities and the re-articulation of youth's bedroom cultures deserves further and more thorough investigation.

The limited sample size also prevents the authors from advancing reflections on how different socio-cultural backgrounds shape tweens' reflexive engagement with consumer and celebrity culture in the context of their identity work.

Finally, the empirical evidence collected so far suggests exploring the issue of inter-generational relationships around the practice of online gaming, dress up, media and material consumption.

Despite those limitations, the study has highlighted not only the use and meanings young girls make out of paper dolls and dress up websites, but also that they are important within tweens' everyday life under many aspects.

First, they represent a tile in the larger media and consumer culture in which children are immersed, and through which they are socialised to celebrity culture and normative gender patterns.

Second, beyond being a gendered online activity, they also represent a game about gender where tweens play with gendered stereotypes and with the girl/ 
woman continuum consisting of the socialisation of patterns of adult femininity, while exposing tween girls to conformist expectations on the appropriate female model. This helps them to cope with making sense of both their changing bodies and age-specific practices.

Third, dress up games embody the complex character of contemporary bedroom culture at the intersection of cross-media practices, individual and collective activities.

In conclusion, hence, stimulating reflexivity on identity performances, normative femininities, the role of both fashion and celebrities, online gaming practices provide girls with a space to make sense of their engagement with consumer culture and its normative patterns (Willett, 2008). Therefore, they are a further example of how "children's culture-in-interaction makes meaning and inequality out of consumption" (Pugh, 2009: 82). 


\section{References}

Boden, S. (2006). Dedicated Followers of Fashion? The Influence of Popular Culture on Children's Social Identities. Media, Culture \& Society, 28(2), 289-298.

Boccia Artieri, G. (2012). Mediologia dei dress up game. In Mascio, A. (ed.), Fashion Games. Moda, gioco e identità. Milano: Angeli, pp. 55-70.

Bronfenbrenner, U. (1979). The Ecology of Human Development. Cambridge, MA: Harvard University Press.

Buckingham, D. (2007). Beyond Technology: Children Learning in the Age of Digital Culture. Cambridge: Polity.

Buckingham, D. (2008). Introducing Identity. In Buckingham, D. (ed.), Youth, Identity, and Digital Media, Cambridge, Mass: The MIT Press, pp. 1-24.

Buckingham, D. (2011). The Material Child: Growing up in Consumer Culture. Cambridge: Polity.

Cook, D. (2004). The Commodification of Childhood: The Children's Clothing Industry and the Rise of the Child Consumer. Durham, NC: Duke University Press.

Cook, D. (2008). The Missing Child in Consumption Theory. Journal of Consumer Culture, 8(2), 219-243.

Corsaro, W. A. (1997). The Sociology of Childhood. Thousand Oaks, CA: Pine Forge Press.

Coulter, N. (2012). From Toddlers to Teens: The Colonization of Childhood the Disney Way. Jeunesse: Young People, Texts, Cultures, 4(1), 146-158.

Denisoff, D. (ed.) (2008). The Nineteenth Century Child and Consumer Culture. Aldershot: Ashgate.

Driscoll, C. (2002). Girls: Feminine Adolescence in Popular Culture and Cultural Theory. New York: Columbia University Press.

Driscoll, C. (2005). Girl Doll: Barbie as a Puberty Manual. In Mitchell, C., Reid-Walsh, R. (eds), Seven Going on Seventeen. Tween Studies in the Culture of Girlhood. New York: Peter Lang, pp. 224-241.

Driscoll, C. (2008.) Girls Today. Girls, Girl Culture and Girl Studies. Girlhood Studies, 1(1), 13-32. 
Drotner, K. \& Livingstone, S. (eds.) (2008). The International Handbook of Children, Media and Culture. London: Sage.

Giddens, A. (1984). The Constitution of Society: Outline of the Theory of Structuration. Cambridge: Polity.

Gill, R. (2003). From Sexual Objectification to Sexual Subjectification: The Resexualisation of Women's Bodies in the Media. Feminist Media Studies, 3(1), 100-106.

Harden, J., Scott, S., Backett-Milburn, K. \& Jackson, S. (2000). Can't Talk, Won't Talk? Methodological Issues in Researching Children. Sociological Research Online, 5(2). Last accessed on 25 September 2013 at URL: http:// www.socresonline.org.uk/5/2/harden.html.

Heath, J. \& Potter, A. (2005). The Rebel Sell: How the Counterculture Became Consumer Culture. Chichester: Capstone.

Ito, M. (2009). Hanging out, Messing around, Geeking out: Kids Living and Learning with New Media. Cambridge: MIT Press.

Jacobson, L. (2004). Raising Consumers: Children and the American Mass Culture in the Early Twentieth Century. New York: Columbia University Press.

James, A., Jenks C. \& Prout, A. (1998). Theorizing Childhood. Cambridge: Polity.

Lemish, D. (2003). Spice World: Constructing Femininity the Popular Way. Popular Music and Society, 26(1), 17-29.

Lincoln, S. (2004). Teenage Girls' Bedroom Culture: Codes versus Zones. In Bennett, A. \& Kahn-Harris, K. (eds.), After Subculture: Critical Studies in Contemporary Youth Cultures. Basingstoke: Palgrave McMillan, pp. 94-106. Lincoln, S. (2013). Media and Bedroom Culture. In Lemish, D. (ed.), The Routledge International Handbook of Children, Adolescents and Media. London: Routledge, pp. 315-321.

Livingstone, S. (1998). Mediated Childhoods: A Comparative Approach to Young People's Changing Media Environment in Europe. European Journal of Communication, 13(4), 435-456.

Livingstone, S. (2002). Young People and New Media: Childhood and the Changing Media Environment. London: Sage.

Livingstone, S. (2009). Children and the Internet. Cambridge: Polity. 
Livingstone, S., Haddon, L., Görzig, A. \& Ólafsson, K. (2011). Risks and Safety on the Internet: The Perspective of European Children. Full Findings. EU Kids Online. London: LSE. Last accessed on 25 September 2013 at URL: http:// lse.ac.uk/EUKidsOnlineReports.

Livingstone, S. \& Helsper, E. (2007). Gradations in Digital Inclusion: Children, Young People and the Digital Divide. New Media \& Society, 9(4), 671-696.

Livingstone, S., \& Haddon, L. (2012). Theoretical Framework for Children's Internet Use. In Livingstone, S., Haddon, L. \& Goerzig, A. (eds.), Children, Risk and Safety online: Research and Policy Challenges in Comparative Perspective. Bristol: The Policy Press, pp. 1-14.

Luke, C. (1989). Pedagogy, Printing, and Protestantism: The Discourse on Childhood. Albany: University of New York Press.

Madden, M., Lenhart, A., Cortesi S., Gasser, U., Duggan, M., Smith, A. \& Beaton, M. (2013). Teens, Social Media, and Privacy. Washington: Pew Research Center.

Marsh J. (2010). Young Children's Play in Online Virtual Worlds. Journal of Early Childhood Research, 8(1), pp. 23-39.

Mazzarella, S. R. (2013). Media and Gender Identities. Learning and Performing Femininity and Masculinity. In Lemish, D. (ed.), The Routledge International Handbook of Children, Adolescents and Media. London: Routledge, pp. 279-286.

McRobbie, A. (1991). Feminism and Youth Culture from Jackie to Just Seventeen. Basingstoke: McMillan.

McRobbie, A. \& Garber. (1976). Girls and Subcultures. In S. Hall and P. Jefferson (eds.), Resistance Through Ritual: Youth Cultures in the Post War Britain. Essex: Hutchinson University Library, pp. 209-22.

McRobbie, A. (2008). Young Women and Consumer Culture. Cultural Studies, 22(5), 531-550.

Mitchell, C. \& Reid-Walsh, J. (eds.) (2005). Seven Going on Seventeen. Tween Studies in the Culture of Girlhood. New York: Peter Lang.

Peers, J. (2004). The Fashion Doll: From Bebe Jumeau to Barbie. Oxford: Berg. Piaget, J. \& Inhelder, B. (1969). The Psychology of the Child. New York: Basic Books. 
Pilcher, J. (2010). What Not to Wear? Girls, Clothing and 'Showing' the Body. Children \& Society, 24, 461-470.

Plumb, J. H. (1982). Children and Consumption. In McKendrick N., Brewer, J. \& Plumb, J. M. (eds.), The Birth of a Consumer Society: The Commercialization of Eighteenth-century England. London: Europa Publications.

Pugh, A. J. (2009). Longing and Belonging: Parents, Children and Consumer Culture. Berkley: University of California Press.

Renold, E. \& Ringrose, R. (2011). Schizoid Subjectivities? Re-theorizing Teen Girls' Sexual Cultures in an Era of 'Sexualization'. Journal of Sociology, 47(4): 389-409.

Russell, R. \& Tyler, M. (2002). Thank Heaven for Little Girls: 'Girl Heaven' and the Commercial Context of Feminine Childhood. Sociology, 36(3), 619-637.

Rysst, M. (2010). 'I am Only Ten Years Old': Femininities, Clothing-fashion Codes and the Intergenerational Gap of Interpretation of Young Girls' Clothes. Childhood, 17(1), 76-93.

Solberg, A. (1996). The Challenge in Child Research: From "Being" to "Doing”. In Brannen, J. \& O'Brien, M. (eds.), Children in Families: Research and Policy. Basingstoke: Falmer, pp. 53-65.

Stuart, A. and Donaghue N. (2012). Choosing to Conform: The Discursive Complexities of Choice in Relation to Feminine Beauty Practices. Feminism \& Psychology, 22(1), 98-122

Zelizer, V. (1985). Pricing the Priceless Child: The Changing Social Value of Children. Princeton: Princeton University Press.

Willett, R. (2008). Consumer Citizens Online: Structure, Agency, and Gender in Online Participation. In Buckingham, D. (ed.), Youth, Identity, and Digital Media. Cambridge, MA: The MIT Press, pp. 49-70. 